\title{
Research on the Cultivation of Industrial Design Students' Practical Ability
}

\author{
CHEN Hong \\ School of Mechatronic Engineering \\ Xi'an Technological University, XTU \\ Xi'an, China \\ Chenhong_xtu@yahoo.cn
}

\author{
WANG Fang \\ School of Mechatronic Engeering \\ Xi'an Technological University, XTU \\ Xi'an, China \\ Wangfang0608@sina.com
}

\begin{abstract}
The cultivation of industrial design students' practice ability can start from three aspects of students, teachers, school. The first method is establishing design team which is starting from students. It increased the students' practice opportunities and mobilized students' initiative and innovative consciousness. The second method is innovating practice teaching mode which is starting from teachers. It explored new teaching mode and evaluation mode and paid attention to course achievements. The third method is perfecting practice teaching platform which is starting from school. School should be a backing for practical teaching.
\end{abstract}

Keywords- industrial design; practice ability; design team; practice teaching mode; practice teaching platform.

\section{INTRODUCTION}

Connotation and denotation of industrial design involves a profound. Industrial design has the edge discipline characteristic including comprehensive, systematic and interdisciplinary. So employees of industrial design must have broad knowledge system and comprehensive ability. Now, industrial design talent internationally recognized should meet the following requirements: the ability to solve problems creatively, the literacy of image thinking and logical thinking in the coexistence, good ability of design performance, making good model, the ability of information collection and processing, computer aided design ability, outstanding ability and skills to communicate with people, design practice and management ability, understanding the whole process from design manufacturing to market of the product, etc.

From the cognitive science and education perspective, innovation starts with problem, and takes its source at practices. Practice teaching helps students to understand, grasp and use the theory of knowledge. Industrial design is the essence of innovation. The cultivation of practice ability plays a decisive role in the cultivation of students' comprehensive ability.The industrial design education has developed a few decades in China. There still have many blemishes. In view of industrial design talent training in xi'an technological university, the above problems are also very prominent. In the research only the following problems are discussed:

1) There is a gap between existing teaching mode and production needs. We should strengthen the cultivation of students practical ability.
2) In this background of school of mechatronic engineering, engineering resources didn't make full use of.

3) There is lack of practical ability training in major courses at existing teaching mode. The class teaching is mainly theory teaching, and pays no attention to practice. Students learn passively and lack of independent innovation.

4) Learning outcomes of course are not timely collation and summary.

According to the status and characteristics of the development of industrial design in xi'an technological university, the cultivation of students' practice ability can start from the three aspects of students, teachers, school. Starting from students, the cultivation should increase the students opportunities to practice, and mobilize students' initiative and innovative consciousness. Starting from teachers, the cultivation should explore innovation teaching and examination mode, combine with practice teaching and scientific research, and pay attention to course achievements. Starting from school, the cultivation should support in hardware and policy, innovate in management. School is as a backing for practical teaching.

\section{ESTABLISH THE MULTIPLE GRADE,}

\section{MULTIDISCIPLINARY, COMPLEMENTARY DESIGN TEAM}

The formation of the design team is student-centered, interesting-centered, task-centered. The design team can fully mobilize students' learning initiative. And it can promote interaction of multiple grade and multidisciplinary students. The teaching mode has enhanced the students'practice ability and comprehensive quality. It is advantageous to train design talents in accordance with social requirements. In practice, the industrial design professional teachers and class teacher can guide and promote the estabishment of design team. The design team also has many different forms to estabish, such as task oriented, multidisciplinary, multiple grade, special design, specific design etc. "Design team" is mainly in the selfmanagement of students and the combination of teacher counseling supervision.

\section{A. The main types of the design team}

1) Design team divided by project: The design team is mainly formed through participation in design practice. This is similar to the project driven teaching. It will add the real business subject to the curriculum teaching, and let students 
participate in the enterprise design projects. In this project driving teaching, the teachers and enterprise designers jointly responsible for guidling students of the team. The design process and the work of students can become the case for next class teaching. It has enriched the teacher's experience and the teaching content. And students like this actual product design case.

2) Multidisciplinaryt design team: The team composes of multidisciplinary students, from industrial design and mechanical engineering. The practice forms include design competition and graduation design. Students of different majors together to complete the product design, it formed a multidisciplinary integrated design team. In the specific design, students from industrial design and mechanical design participate in product concept design and structure design. After the mechaniam students complete product structure analysis and finite element analysis, the mold professional students complete the mold design of the product part. Under the guidance of the teacher, the students of different majors participate in different work. They learn from each other. During the design process, students actively learned a lot of knowledge and teamwork, and they maked progress together.

3) Multiple grade design team: The team mainly consists of industrial design students in different grades. The members have common interests, which makes learning more efficient. Multiple grade design team can be divided by the special design field or interest. For example, the visual design team, color design team, model manufacture team, experience design team, modeling team etc. The design practice forms is mainly discipline competition, design competition and undertaking the related design project.

\section{B. The main characteristics of the design team}

1) Emphasizes the initiative: Active degree reflects one person's attitude how he looks at the world. It is the important influence factor to accomplish anything. The students who enjoy the design team should ensure their own initiative. Firstly, they should pay attention to the daily class learning in order to tamp the foundation. Then they can actively participate in all the work of design team. Only that can they ensure an all-round development ${ }^{[1]}$.

2) Humanization, team and open: This is reflected in that integrating teacher counseling supervision into students' self management. The professional teacher and leader of the subject will occasionally direct and supervise the working study life of the design team. They will give the rectification to the team. Members of the design team put forward all kinds of problems in the practice. Based on the macro management mode, the student responsible person, who has be careful to pick out from the team, will be in charge of each transaction. The project will also be open to the students who didn't enjoy the design team. The students can be from industrial design or other major. The project will get a very good solution through the teamwork and multidisciplinary cooperation, which will also cultivate students' cooperation ability.

3) Complementarity: Students of different grades have different professional foundation and different professional quality. Students in different majors have different knowledge structure. And all the students are different in experience, hobbies, personality and specialty. So, students can be complementary and mutualeffect through the daily common learning, work and practice. The design team provides a platform for students. The platform is belong to the students own group, though which they can display their talent and improve their professional skills.

\section{EXPLORE OPEN INNOVATIVE PRACTICE TEACHING MODE}

The open innovative practice teaching system of industrial design is based on design expression and operation skill. The system focuses on the product design and relies on the design training and design research. Each link practice teaching should progressive develop from four levels: universal basic practice, discipline basic practice, specialty practice and innovation design practice ${ }^{[2]}$. At the same time, practice teaching and the class teaching of design courses are complementary.

The practice teaching system is complete, standard, easy operation and keeping pace with the times. In addition to structuring the system, it is more important to increase practice in major course, to improve the interactive in class and to stimulate students' innovation consciousness. Exploration on an open innovation practice teaching mode should combine with the characteristics of the industrial design specialty and design practice courses. At the same time, it should reform teaching mode and the evaluation system, administrate the course achievements.

\section{A. Innovation of class teaching model}

The traditional teaching mode makes the design major courses, which should have very strong interaction in the class, become quite satisfactory. And it makes students lack of independent innovation and learning initiative. An open innovation practice teaching mode includes the following forms at least:

1) Diversified teaching mode: In addition to the traditional teaching, the class can also be interspersed seminar, practice teaching and other forms. There are literature reading, collection of data, interview survey, group interaction, achievement report and other activities after class. Students always can share their views with the class, and they have the opportunities for dialogue throughout the design class.

2) Subject teaching model: A comprehensive project contains all main knowledge points of the course. During teachers explain this comprehensive subject in class, they are showing the knowledge of modular course gradually. 
According to new product development flow and its key steps, the course content will be distributed to the whole development process. Then all the course content will form systematic design project ${ }^{[3]}$. The method enables students to further understand the curriculum content and curriculum position in industrial design. And it is complementary to the knowledge of other development stages, that is better for thinking of the whole design.

3) The combination of classroom teaching and practice: Teachers should add the actual scientific research project in training course or as case teaching. The design subject would be set by employment company and teachers together. The method will be propitious to share the design experience.

\section{B. Innovation of curriculum evaluation model}

In the traditional teaching mode, the students passively accept the results evaluation of existing. And the important role of evaluation, as a learning process to improve, was ignored. The curriculum evaluation model should be reformed to make evaluation equity, comprehensive and interactive. Here are some specific methods and forms as follows.

1) Dispersing assessment: According to the characteristics of curriculum and course syllabus requirements, the evaluation system should establish a reasonable proportion of the score to strengthen assessment at the learning process. Total mark not only is from the midterm grade and final exam grade, but also includes regular grade and oral interview grade etc. The regular grade involves written assignments, practical tests, perfarmance in class and attendance rate, etc. The forms of performance evaluation should not limited to written examination. Course test such as short thesis or course assignments, can also be used as a means of examination. Various types of examinations can effectively relieve the pressure on students, teachers and school ${ }^{[4]}$. Dispersing assessment and various types of examinations will encourage and promote student learning.

2) Interactive evaluation system: The assessment of design course is mainly course assignments. The traditional assignment evaluation was completed by the teacher alone. The interactive evaluation system has changed the traditional way of evaluation. The teacher will evaluate the students' work together with some students. Or, the students' work will be evaluated though a small work conference. Teacher will reassert the subject, scope of design and design requirements of this assignment before the conference. And students should publish his works one by one at the stipulated time. At the conference, student should interpretateof his works according to the requirements, including investigation, source of design ideas, design concept, design intent, the design highlights and so $\mathrm{on}^{[3]}$. The teacher and other students are as audience and judge. During the process, teacher's main role is chairperson. Teacher should evaluation the work on student's view and give the guide along the student's thought, so as to actively encourage students. Other students can put forward their opinions and suggestions for discussion together.

3) Comprehensive evaluation: Comprehensive design course can employ several progress reports and evaluation, so as to make the process more detailed and comprehensive. That fully embodies fairness and comprehensive evaluation. Including the specific evaluation form: Mutual evaluation between students; For all the teachers, giving score after discussion in teaching group and communicate with students; Social Interaction Evaluation: customers and proficients are invited to participate in the evaluation. The level and quality of work completed and team defense score are put together to determine the final performance.

\section{Manage curriculum results}

The traditional teaching mode wasn't consolidation and keeping awareness for outcome of the course. The time of a course is limited. The outcome completed in course has been rejected after the end of the course. Many good achievements have not been collected, and some improvement subject also settle a matter by leaving it unsettled. The design results of the course should be pieced together or for the protection of property rights. Unsolved topic in the course can be reused or as background information in the subsequent practice.

\section{BUILD AND PERFECT THE OPEN PRACTICE TEACHING PLATFORM}

The open practice teaching platform consists of the intramural practice teaching platform and the extramural practice teaching platform. The intramural practice teaching platform include the school-level practice center, studio, professional computer room, laboratory, model studio etc. Here will be developed the design skills training, course experiment and computer training. The intramural practice teaching platform also assumes a variety of teaching activities such as metalworking practice, curriculum design, the design of special topic. The extramural practice teaching platform mainly refers to the practice base and the characteristic design practice base outside school, which established links with the school. It undertakes the production practice, professional design practice and graduation practice, etc.

\section{A. Perfect the intramural practice teaching platform}

Now the laboratory of industrial design includes manmachine engineering laboratory, product model studio, innovation laboratory and design expression laboratory. Industrial design focus on the design planning for industrial products. Model and prototype is the best way to inspection the product design capacity. The model or prototype is more approaching the design scheme in shape, structure, function, the more with test value. The existing model experiment has no difference in content for the engeering industrial design 
and art industrial design. In the utility, preliminary manual representation the basic appearance of the product designed. The structure, function of products can't reproduce. The utility is not high for the cultivation of students' practice ability. In view of the present situation of industrial design laboratory in school of mechatronic engineering, the development of new experiment by integration all available resources, is the way to improve the effectiveness of experiment.

1) Strengthen cooperation with electronic laboratory of mechanical engineering: Product model can be turned into real available products by increasing mechanism and electron design. The students from different majors can improve their practical ability though the form.

2) In the environment of school of mechatronic engineering, bringing new technology and new equipment to model making laboratory, that let the students understand the subject development trends.

3) Digital simulation technology would be used to practice teaching. The virtual experiment can be developed. It is the innovation practice of the latest scientific research results.

\section{B. Perfect the extramural practice teaching platform}

The existing production practice bases is single, mainly large-scale manufacturing enterprises. It can't embody the professional characteristics of industrial design. Industrial design should have its own practice teaching platform with product design characteristics. After establishing contact with a number of enterprises, students would take in simulation design training in real environment though practical subject and actual operation. They will obtain communication and team cooperation ability in enterprise. The practice education base is an important link for industrial design education. It is available from the following aspects to build and perfect the extramural practice teaching platform.

1) The relationship with different types of design company should be strenghened and long-term. The practice education base with characteristics of industrial design should be expanded by multi-directional and multi-channel, for the establishment of long-term mechanism of the production, learning and research cooperative education.

2) Outstanding experts from cooperative enterprise will be engaged as part-time teacher. And the full-time teacher will be selected as representative to the cooperative enterprise for production, learning and research cooperation. various types of growth mechanism of teachers will come into being, such as communication training, cooperative teaching, part-time teaching, etc.

3) The first task of industrial design in China is to culture industrial designers with a global view. Industrial design students should have delicate perception for the new technology and method. They should pay attention to the early data and information collection and arrangement during task design. So as to gain a good understanding of the history, current situation and future development of the objective product.

The school-enterprise cooperation teaching mode have expanded the content and field of practice teaching. Students can directly obtain experience at the research projects in enterprises, that is the supplement of classroom teaching. They will acquire the most advanced knowledge though it. All that has important significance for both the development of industrial design subject and the development of enterprise productivity. Enterprises can take full advantage of the rich and vibrant ideas from students and their advisors, and students can get a lot of knowledge which can't be learned in school.

\section{CONCLUSION}

The paper discussed the main ways of cultivating engeering industrial design students' practical ability from three aspects as follows. The first way is establishing design team, and it starts from the main body of students. The method improved the students' practical ability by increasing opportunities for practice and mobilizing students' initiative. The second one is to explore open innovative practice teaching mode, which starts from teachers. The practice teaching mode is reformed though teaching mode innovation, reform of the examination evaluation system and paying attention to course achievement. The third is to build and perfect the open practice teaching platform, which starts from school management. It put forward multi-directional, multi-channel expansion of the practice teaching platform, by software and hardware construction, cooperation with different major, school-enterprise cooperation, information sharing, etc. The practice ability of students will be greatly improved if these three aspects were done. And College education can be better satisfy the enterprise requirement. Education can be better integrated with the society.

\section{ACKNOWLEDGMENT}

This research was supported by teaching reform item funds of the Xi'an Technological University and granted No.12JGZ03.

\section{REFERENCES}

[1] ZHOU Meili, LI Yajun, "Exploration of design education cultivating model, the studio model of complementary study about multi-grade students in industrial ddesign,” Art and Design, Beijing, 2010, (3): 133-135, in chinese.

[2] LIANG Xun, ZHOU Xing, "Research on framework of practical teaching system for industrial design in multidisciplinary universities,” Experimental Technology and Management, Beijing, Vol. 28, pp. 163-165, June 2011, in chinese.

[3] WU Yanfang, XUE Yong, CHENG Kun, YANG Lei, "Exploration on instructional mode of industry design," 3rd Conf. ETT, pp.242244, 2010, in chinese.

[4] SHEN Mingqian, "Reform and practice of assessment methods for professional courses in industrial design,” Journal of Jiangsu Teachers University of Technology, Changzhou, vol. 17, pp. 80-83, June 2011, in chinese. 